\title{
Estudio para la instalación de un centro de hemodiálisis en la ciudad de Lima
}

\author{
Ana Lucía Mendiola Iparraguirre* \\ Christian Giancarlo Callirgos Santos* \\ Universidad de Lima. Lima, Perú
}

Recibido: 28 de marzo de 2014/ Aprobado: 7 de abril de 2014

REsumen: La enfermedad renal crónica terminal (ERCT) afecta a gran cantidad de personas en todo el mundo, y si no se recibe un tratamiento adecuado, puede llevar a la muerte. El presente artículo es un estudio para la instalación de un centro privado de hemodiálisis en la ciudad de Lima dirigido a pacientes de EsSalud, institución que atiende al $95 \%$ de personas que sufren de esta enfermedad, pero cuya infraestructura y servicios hospitalarios no son suficientes para tratar directamente a todos sus pacientes, por lo que terceriza el $56 \%$ del servicio. Dicho centro se llevaría a cabo a través de una licitación pública.

Palabras clave: enfermedad renal crónica terminal (ERCT) / diálisis / dializador / ósmosis / servicio tercerizado

\section{Study for the installation of a Hemodialysis Center in Lima}

Abstract: Terminal Chronic Kidney Disease (TCKD) is a disease that affects a large number of people around the world and, if not received proper treatment, can lead to death. This article has as main objective the installation of a private Hemodialysis center in Lima targeting patients from EsSalud, serving 95\% of people suffering from this disease, but whose infrastructure and hospital services are not sufficient to meet directly to all their patients, so that $56 \%$ of the service is outsourced. This will be done through a public tender.

Key words: terminal chronic renal disease (TCRD) / dialysis / dialyzer / osmosis / outsourcing service

* Correos electrónicos: almendiola@gmail.com, xtian.c@gmail.com. 


\section{ANTECEDENTES Y MARCO TEÓRICO}

La enfermedad renal crónica (ERC) consiste en la incapacidad de los dos riñones de cumplir adecuadamente sus funciones: eliminar impurezas, toxinas y líquidos sobrantes del torrente sanguíneo. Existen cinco estadios de ERC dependiendo de la intensidad de la enfermedad. El estadio más avanzado es la enfermedad renal crónica terminal (ERCT), en el que para su sobrevivencia los pacientes requieren costosos tratamientos de reemplazo o sustitución de la función renal. Entre sus causas principales se encuentra la diabetes mellitus, la hipertensión arterial y la glomerulonefritis.

Como método de sustitución renal se realiza la hemodiálisis, procedimiento invasivo por el cual se eliminan los desechos y el exceso de sal y de agua, manteniendo un nivel adecuado de múltiples sustancias químicas, lo cual contribuye a controlar la presión arterial.

Figura 1

Estadios de la enfermedad renal

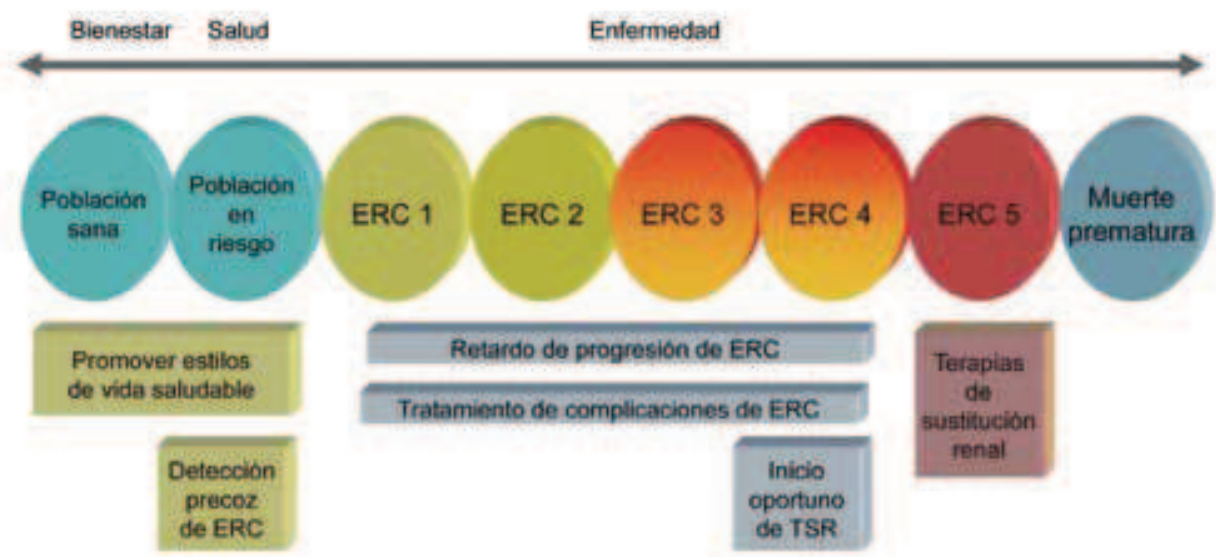

Fuente: Centro Nacional de Salud Renal-EsSalud (2011). 


\section{ESTUDIO DE MERCADO}

\subsection{Definición del servicio}

El servicio consiste en instalar y poner en funcionamiento un centro de hemodiálisis para tratar parte de la demanda desatendida, buscando principalmente que EsSalud tercerice sus servicios con el centro, ya que este concentra la mayor cantidad de pacientes con nefropatía crónica.

Dado que son más de ochenta las clínicas que tienen contrato anual con EsSalud en todo el país, la mayoría de las cuales se concentran en Lima, el nuevo centro debe diferenciarse brindando servicios de mejor calidad dentro del rango de precios de la competencia y dando al asegurado la alternativa de optar por servicios complementarios por un pago adicional.

\subsection{Situación relativa en el mercado}

Al tratarse del tratamiento de una enfermedad crónica, no existen muchos tratamientos sustitutos. Entre los existentes se tiene la diálisis peritoneal, que no se encuentra muy difundida a escala mundial y que requiere del entrenamiento del paciente para poder autoasistirse. Asimismo, está el trasplante de riñón, que tiene como principales complicaciones el rechazo por parte del organismo del receptor e infecciones debido a un exceso de fármacos inmunodepresores una vez realizado el trasplante. Sin embargo, toma muchos años esperar por un donante adecuado.

Es importante resaltar que la ERC es originada por enfermedades como la diabetes mellitus, glomerulonefritis y la inflamación de las vías urinarias. Además, la enfermedad puede presentar complicaciones como hipertensión arterial, anemia, dislipidemia, enfermedad ósea, desnutrición, etcétera. Por lo tanto, los productos complementarios para el servicio son los tratamientos adicionales y medicamentos empleados para el tratamiento de estas enfermedades.

\subsection{Análisis de la demanda}

Del total de pacientes con ERCT que reciben tratamiento, EsSalud debe atender aproximadamente al $95 \%$ y las otras entidades: Minsa, Fuerzas Armadas y servicios privados, atienden al $5 \%$ restante. 
Aproximadamente el $85 \%$ de estos pacientes se trata mediante la hemodiálisis; sin embargo, la infraestructura y los servicios hospitalarios de EsSalud son insuficientes para brindar directamente el tratamiento a todos sus pacientes, por lo que la institución terceriza el $56 \%$ del servicio con clínicas a través de contratos anuales.

En el Perú, basándonos en las guías del KDOQI \& NHANES III Study (The National Kidney Foundation Disease Outcomes Quality Initiative-National Health and Nutrition Examination Survey), se estima que aproximadamente el 10.9 \% de la población del país presenta insuficiencia renal crónica.

Siguiendo el mismo índice, se obtiene que el $0.1 \%$ del total de la población se encuentra en el estadio 5 , es decir, que requiere de un tratamiento de sustitución o reemplazo de la función renal.

Con estos porcentajes y la información del INEI en el 2012, se calculó la cantidad de pacientes que sufrirían de disfunción renal crónica.

Tabla 1

Total de pacientes en estadio 5 al 2012 en el Perú

\begin{tabular}{|c|}
\hline Población total del Perú en el año 2012 \\
\hline $30,135,875$ habitantes \\
\hline Pacientes con ERC (10.9\%) \\
\hline $3,284,811$ pacientes \\
\hline $\begin{array}{c}\text { Pacientes en estadio } 5 \\
(0.1 \% \text { de la población total) }\end{array}$ \\
\hline 30,136 pacientes \\
\hline
\end{tabular}

Fuente: INEI (2013).

Elaboración propia.

Solo el $34.2 \%$ de la población peruana se encuentra asegurado, esto equivale para el 2012 a 10,302 pacientes en estadio 5. Por lo tanto, en ese año existió una población desatendida de 19,834 pacientes. 
En la siguiente tabla se puede apreciar un estimado de la demanda insatisfecha, es decir, de población desatendida hasta el año 2012.

Tabla 2

Demanda insatisfecha estimada en el Perú

\begin{tabular}{lccccc}
\hline Año & $\begin{array}{c}\text { Población } \\
\text { total }\end{array}$ & $\begin{array}{c}\text { Población } \\
\text { con ERCT }\end{array}$ & $\begin{array}{c}\% \text { De } \\
\text { pacientes } \\
\text { asegurados }\end{array}$ & $\begin{array}{c}\text { Pacientes } \\
\text { asegurados }\end{array}$ & $\begin{array}{c}\text { Población } \\
\text { desatendida }\end{array}$ \\
\hline 2006 & $28,151,443$ & 28,151 & 24.1 & 6,781 & 21,371 \\
2007 & $28,481,901$ & 28,482 & 25.1 & 7,150 & 21,332 \\
2008 & $28,807,034$ & 28,807 & 27.9 & 8,035 & 20,772 \\
2009 & $29,132,013$ & 29,132 & 29.4 & 8,572 & 20,561 \\
2010 & $29,461,933$ & 29,462 & 30.8 & 9,081 & 20,380 \\
2011 & $29,797,694$ & 29,798 & 32.2 & 9,609 & 20,188 \\
2012 & $30,135,875$ & 30,136 & 34.2 & 10,302 & 19,834 \\
\hline
\end{tabular}

Fuente: INEI, EsSalud (2013).

Elaboración propia.

\subsection{Análisis de la oferta}

La oferta de las unidades de hemodiálisis ha sido superada por la sobredemanda de pacientes con necesidad de un tratamiento de sustitución renal.

El servicio de hemodiálisis es brindado por EsSalud, que cubre íntegramente el tratamiento de sus asegurados. En la actualidad, EsSalud tiene a cargo el $95 \%$ de los pacientes que reciben tratamiento de diálisis por insuficiencia renal crónica terminal en el Perú. Cuenta con una red aproximada de 85 centros de hemodiálisis, 38 de ellos propios y 47 centros contratados.

La proyección de la oferta está restringida por las bases para la contratación del servicio de atención ambulatoria de hemodiálisis establecidas por EsSalud, que solo permiten un máximo de tres módulos por centro. 
Cada módulo está conformado por cinco máquinas de hemodiálisis y debe tener una de respaldo en caso de emergencias o falla de alguna máquina.

Asimismo, las bases permiten atender hasta un máximo de cuatro turnos por día, no obstante, la atención en cuatro turnos generaría mayores costos en mano de obra y un deterioro más rápido de las máquinas, por lo que nuestro centro contaría con tres módulos que trabajarían tres turnos cada uno:

- Primer turno: 8:00 - 12:00 horas

- Segundo turno: 13:00 - 17:00 horas

- Tercer turno: 18:00 - 22:00 horas

Se asume que la oferta sería fija, ya que inicialmente EsSalud brindaría la totalidad de pacientes que pueda cubrir nuestra capacidad que equivale al tratamiento de 45 pacientes diarios. Cabe resaltar que los pacientes podrán solicitar a EsSalud atenderse en un centro específico o cambiar de centro de acuerdo a la disponibilidad.

De 45 pacientes diarios, habría 90 pacientes fijos cuya atención sería en dos grupos: lunes-miércoles-viernes y martes-jueves-sábado.

\subsection{Determinación de la demanda para el proyecto}

Para este proyecto se buscará un público que desee un servicio adicional al momento de realizarse el tratamiento y esté dispuesto a pagar por este. Por ello, el mercado meta está conformado por los pacientes con enfermedad renal crónica terminal de los sectores socioeconómicos A y B que sean atendidos por EsSalud, para esto se ubicaría el local en un lugar que se acomode a las necesidades de estos sectores. Asimismo, se concluyó que el distrito más adecuado para la instalación y puesta en marcha del centro de hemodiálisis es Santiago de Surco.

De acuerdo a las bases de EsSalud para la contratación del servicio de atención ambulatoria de hemodiálisis, se puede tener un máximo de tres módulos de atención por centro. Estos deben de contar con una capacidad de cinco puestos de hemodiálisis que trabajen hasta tres turnos cada uno, pudiéndose atender en total a 45 personas por día que equivalen al tratamiento de 90 pacientes, manteniéndolos, a lo largo de las semanas, en dos grupos de 45: lunes-miércoles-viernes y martesjueves-sábado. 
En la actualidad, de acuerdo con las bases para la contratación del servicio de atención ambulatoria de hemodiálisis, EsSalud ofrece un monto aproximado de S/. 169.37 (sin IGV) por sesión. Además, se debe tener en cuenta que paga diferentes montos a los centros, de acuerdo con el contrato firmado.

\subsection{Dimensionamiento del servicio}

Teniendo en cuenta que la capacidad máxima permitida por EsSalud es de tres módulos de atención por centro de hemodiálisis, se atenderá a 15 pacientes por turno (tres turnos diarios), quienes deberán atenderse tres veces por semana, Asimismo, solo se necesitará una capacidad total de atención de 90 pacientes.

Por lo tanto, el mercado no significa impedimento alguno para el tamaño del servicio que se desea establecer, según se puede ver en la siguiente tabla, donde se muestra el pronóstico de pacientes hasta el año 2020:

Tabla 3

Total de pacientes con ERCT en EsSalud

\begin{tabular}{cc}
\hline Año & $\begin{array}{c}\text { Total de } \\
\text { pacientes }\end{array}$ \\
\hline 2012 & 9,787 \\
2013 & 10,305 \\
2014 & 10,860 \\
2015 & 11,415 \\
2016 & 11,970 \\
2017 & 12,525 \\
2018 & 13,080 \\
2019 & 13,635 \\
2020 & 14,190 \\
\hline
\end{tabular}

Elaboración propia.

Asimismo, los recursos y las tecnologías necesarios para el centro de hemodiálisis tampoco son limitaciones para su instalación. 


\section{DETERMINACIÓN DEL TAMAÑO DEL SERVICIO}

La relación tamaño-punto de equilibrio se halla obteniendo los costos fijos, que son la mano de obra directa e indirecta y los servicios fijos; los costos variables, conformados por los insumos y otros materiales y servicios adicionales. Por otro lado, el precio es el establecido por EsSalud, el cual asciende a S/. 169.37 (sin IGV).

Teniendo como limitante solo poder atender 45 sesiones diarias, es decir 1,170 atenciones por mes aproximadamente, el punto de equilibrio es el siguiente:

Punto de equilibrio: $\frac{\text { Costos fijos }}{\text { Precio-costo variables }}=\frac{93,592.71}{169.3740 .99}=729.02$ diálisis $/$ mes

El punto de equilibrio es de aproximadamente 729 diálisis al mes, es decir, 28 diálisis al día, lo que equivale a atender 56 pacientes en total.

Cabe mencionar que por cada hemodiálisis, con un costo aproximado de S/. 120.98 soles y un precio de S/. 169.37, se tiene un margen de ganancia de $28.6 \%$.

\section{INGENIERÍA DE PROYECTO}

\subsection{Especificaciones técnicas del servicio}

El centro de diálisis tendrá como función principal ofrecer el tratamiento de hemodiálisis a pacientes asegurados de EsSalud, por lo que deberá contar con los siguientes ambientes: una sala de hemodiálisis, salas de reprocesamiento (sala de lavado de dializadores y de almacenamiento y cebado de dializadores), área biocontaminada, cuarto biocontaminado, área limpia, cuarto limpio, sala de tratamiento de agua, almacén, sala de mantenimiento de máquinas, consultorio y sala de espera.

Del mismo modo, se requerirá el siguiente recurso humano: médico especialista en nefrología, enfermero jefe, enfermero asistencial, técnico de enfermería para la sala de tratamiento, técnico de enfermería 
para la sala de reprocesamiento, nutricionista, psicólogo, asistente social, técnico de mantenimiento de máquinas y personal administrativo.

Por último, entre los principales insumos para el centro tenemos los siguientes: filtros sintéticos semipermeables (también llamados dializadores), soluciones concentradas de bicarbonato de sodio, ácido acético, puristeril (ácido paracético) y suero fisiológico. Todos estos insumos deben ser adquiridos en los proveedores registrados en la Dirección General de Medicamentos, Insumos y Drogas (Digemid) y contar con registro sanitario.

\subsection{Consideraciones sobre la vida útil del proyecto}

Se consideró una vida útil de cuatro años, en la medida en que el monto de la inversión no requiere una evaluación mayor. Luego de recuperada la inversión, los flujos se mantienen constantes, ya que la cantidad de hemodiálisis realizadas es siempre la misma.

El centro de hemodiálisis tendría un programa de operaciones basado en la frecuencia de atención a los pacientes, el cual consistiría en tres turnos de 15 sesiones por día, 6 días a la semana, que da como resultado aproximadamente 1,170 sesiones por mes.

\subsection{Proceso de prestación del servicio}

\subsubsection{Descripción del proceso}

\section{a) Servicio de hemodiálisis}

El servicio se inicia con la llegada del paciente al centro de hemodiálisis y pasa a la sala de espera, para ser atendido en el consultorio.

Una vez en el consultorio, el médico nefrólogo llena la historia clínica del paciente, donde se indica su peso y presión arterial, se calcula la cantidad de líquido que se va a retirar y se registra su asistencia en el Libro de Ocurrencias Médicas, mediante su firma o huella digital.

Después de pasar por este proceso, el paciente ingresa a la sala de hemodiálisis, donde es ubicado en su puesto respectivo previamente acondicionado. Se le conecta a la máquina de hemodiálisis mediante su fístula o catéter y se programan los perfiles de ultrafiltración y conductividad, según el estado del paciente y la cantidad de líquido que se le 
debe retirar. Para que la sangre no se coagule en el sistema se le debe suministrar heparina. Esta parte del proceso es realizada por el enfermero asistencial con el apoyo del técnico de enfermería.

Después de aproximadamente tres horas y media a cuatro horas de tratamiento, se desconecta al paciente de la máquina. Durante este periodo las enfermeras asistenciales se encargarán de supervisar sus módulos asignados.

Finalizado el tratamiento, se le debe dar al paciente una dosis de vitaminas $\mathrm{B}$ y $\mathrm{C}$, por cuanto al estar ambas unidas a las proteínas se pierden durante el proceso. El paciente puede reposar, si así lo requiere, luego es pesado y se le toma la presión arterial como medidas de control. Finalmente, se coordina la siguiente cita y el paciente procede a retirarse.

Durante todo el proceso descrito, se le ofrecerá al paciente distintos servicios que tendrán como finalidad otorgarle mayor calidad y elevar la satisfacción durante el tratamiento.

Una vez que el paciente se haya retirado de la Sala de Hemodiálisis, las auxiliares retiran las sábanas y demás insumos que se utilizaron en la sesión y desinfectan los sillones para los próximos pacientes, mientras tanto los técnicos proceden a iniciar el programa de lavado y desinfección de la máquina que tiene una duración aproximada de treinta minutos; finalmente, retiran los filtros y los llevan a la Sala de Reprocesamiento Biocontaminada, donde son lavados.

Todos estos procesos son supervisados por el enfermero jefe, quien estará a cargo de la documentación de las incidencias respectivas.

En la siguiente tabla se calculan los tiempos estimados de las principales actividades del proceso: 
Tabla 4

Tiempos estimados de actividades principales

\begin{tabular}{|c|c|c|c|c|c|}
\hline Actividad & $\begin{array}{c}\text { Tiempo } \\
\text { (min.) }\end{array}$ & Cant. & Unidad & $\begin{array}{l}\text { Tiempo } \\
\text { total } \\
\text { (min.) }\end{array}$ & Responsable \\
\hline Consulta médica & 5 & 15 & Paciente & 75 & Médico \\
\hline $\begin{array}{l}\text { Conexión de } \\
\text { paciente }\end{array}$ & 5 & 15 & Paciente & 75 & $\begin{array}{l}\text { Enfermero } \\
\text { asistencial }\end{array}$ \\
\hline $\begin{array}{l}\text { Programación de } \\
\text { máquina HD }\end{array}$ & 3 & 15 & Paciente & 45 & $\begin{array}{l}\text { Técnico de } \\
\text { enfermería para } \\
\text { tratamiento }\end{array}$ \\
\hline $\begin{array}{l}\text { Supervisión de } \\
\text { pacientes }\end{array}$ & 21 & 15 & Paciente & 315 & $\begin{array}{l}\text { Enfermero } \\
\text { asistencial }\end{array}$ \\
\hline $\begin{array}{l}\text { Suministro de } \\
\text { vitaminas }\end{array}$ & 2 & 15 & Paciente & 30 & $\begin{array}{l}\text { Enfermero } \\
\text { asistencial }\end{array}$ \\
\hline $\begin{array}{l}\text { Desconexión del } \\
\text { paciente }\end{array}$ & 3 & 15 & Paciente & 45 & $\begin{array}{l}\text { Enfermero } \\
\text { asistencial }\end{array}$ \\
\hline $\begin{array}{l}\text { Toma de presión } \\
\text { y peso }\end{array}$ & 3 & 15 & Paciente & 45 & $\begin{array}{l}\text { Enfermero } \\
\text { asistencial }\end{array}$ \\
\hline $\begin{array}{l}\text { Programación } \\
\text { de limpieza de } \\
\text { máquina }\end{array}$ & 3 & 15 & Máquina & 45 & $\begin{array}{l}\text { Técnico de } \\
\text { enfermería para } \\
\text { tratamiento }\end{array}$ \\
\hline $\begin{array}{l}\text { Retirar sábanas } \\
\text { y limpieza de } \\
\text { puestos }\end{array}$ & 3 & 15 & Puesto & 45 & $\begin{array}{l}\text { Enfermero } \\
\text { asistencial }\end{array}$ \\
\hline Limpieza de filtros & 10 & 15 & Filtro & 150 & $\begin{array}{l}\text { Técnico de } \\
\text { enfermería para } \\
\text { reprocesamiento }\end{array}$ \\
\hline
\end{tabular}

Elaboración propia. 


\section{b) Proceso de purificación del agua}

El proceso de purificación del agua se inicia con el paso del agua por un filtro de carbón activado para eliminar el cloro y los olores y sabores, luego por un filtro de cuarzo que retiene el $\mathrm{CO}_{2}$, las partículas y los sólidos en suspensión, y por un filtro catiónico que elimina iones de magnesio y calcio; después se realiza la ósmosis inversa, donde quedan retenidos cationes, aniones y material orgánico, finalmente se pasa por un filtro de rayos UV que funciona como desinfectante o germicida.

En la ósmosis inversa, para forzar el paso del agua que se encuentra en la corriente más concentrada a la corriente de agua con baja concentración, es necesario presurizar el agua con mayor concentración a un valor superior al de la presión osmótica. Como consecuencia de este proceso, la corriente de agua concentrada se concentrará aún más.

\section{c) Proceso de desinfección del filtro (dializador)}

El reprocesamiento de dializadores debe ser realizado con el mayor cuidado posible, con el fin de no causar daño alguno al paciente y de mantener la eficacia de los dializadores reprocesados. El dializador solo podrá ser reutilizado si el volumen de su cámara interna se mantiene sobre el $80 \%$ del inicial y/o hasta un máximo de veinte veces. Este reprocesamiento debe realizarse en forma estandarizada, ya sea manual o automáticamente. El agua que se va a utilizar, tanto para el lavado del dializador como para diluir los desinfectantes, debe ser procesada por ósmosis inversa de la misma calidad que se utiliza para el tratamiento de hemodiálisis. Antes de reutilizar los dializadores para el tratamiento del paciente, se debe comprobar que queden libres de agentes esterilizantes luego del lavado, verificándose mediante pruebas de detección de químicos residuales. Finalmente, los dializadores deben ser cebados con suero fisiológico para ser almacenados.

El reprocesamiento del filtro se puede dividir en las siguientes etapas:

- Reprocesamiento. Una vez terminado el tratamiento el dializador se limpia, se comprueba y a continuación se llena con un germicida (Puristeril).

- Durante la fase de limpieza, se busca eliminar cualquier residuo de sangre que haya quedado en el dializador al final del tratamiento. 
- Se realiza una prueba de volumen para asegurarse de que las fibras que llevan la sangre estén abiertas y no coaguladas. Si el dializador falla en la prueba de volumen, este será desechado y se procederá al procesamiento previo de un dializador nuevo para el próximo tratamiento.

- Se lleva a cabo una prueba de presión en el dializador para asegurarse de que las fibras que llevan la sangre no estén rotas. Si el dializador falla en la prueba de presión, será desechado y se procederá al procesamiento previo de un dializador nuevo para el próximo tratamiento.

- El dializador es llenado con germicida (Puristeril).

Estos pasos son llevados a cabo por medio de un equipo automático, el cual permite repetir el proceso una y otra vez sin errores.

Existe un expediente detallado por cada dializador reutilizado. En él se muestra cada uno de los pasos a los que se ha sometido el dializador, las fechas, los resultados de las pruebas y el nombre o las iniciales del técnico que reprocesó el dializador. Estos expedientes son mantenidos electrónicamente o también pueden ser hechos manualmente.

- Inspección. Una vez que el dializador ha sido reprocesado, el técnico de reprocesamiento procederá a la inspección visual para comprobar lo siguiente:

- Confirmar que el nivel (volumen) del germicida en el dializador sea suficiente.

- Confirmar que las compuertas de sangre y dializado estén debidamente tapadas y que no haya fugas.

- Revisar para tener la seguridad de que no haya daños ni fugas en el dializador.

- Verificar que tanto el interior como la parte externa del dializador luzcan limpios.

- Rotulado. Luego de haber pasado la inspección, el técnico procederá a fijar una etiqueta nueva en el dializador en la que aparecerá los siguientes datos:

- Nombre del paciente.

- El número de veces que ha usado el dializador. 
- La fecha y hora en las que el dializador fue reprocesado por última vez.

- Las iniciales de la persona que reprocesó el dializador.

- Almacenamiento. Una vez que el dializador ha sido reprocesado, inspeccionado y rotulado, el técnico lo guardará en un área limpia y segura hasta que llegue el momento de ser utilizado nuevamente.

- Inspección y prueba de presencia. Antes de preparar el dializador para ser usado, el personal de diálisis deberá inspeccionarlo nuevamente y llevar a cabo las siguientes pruebas:

- Verificar que el germicida estuvo suficiente tiempo dentro del dializador.

- Confirmar que el nivel (volumen) del germicida en el dializador sea suficiente.

- Verificar que el dializador esté correctamente rotulado y que haya pasado todas las pruebas a las que fue sometido durante su reprocesamiento. El nombre del paciente también deberá aparecer correcta y claramente impreso en la etiqueta.

- Asegurarse de que las compuertas de la sangre y del dializado esten tapadas y no haya fugas.

- Inspeccionar visualmente que luzcan limpios y con buena apariencia tanto el interior como el exterior del dializador.

- Llevar a cabo una prueba de presencia para verificar que el concentrado del germicida en el dializador sea efectivo.

- Enjuague y comprobación residual. Antes de comenzar el tratamiento, el personal deberá enjuagar el germicida del dializador y llevar a cabo otra prueba con el fin de asegurarse de que el enjuague ha eliminado todo el germicida.

- Postratamiento. Después de que el tratamiento haya concluido, el dializador será tapado y enviado al cuarto de reprocesamiento, donde el dializador será reprocesado, y el ciclo se repetirá. 
Figura 2

Diagrama de servicio de hemodiálisis

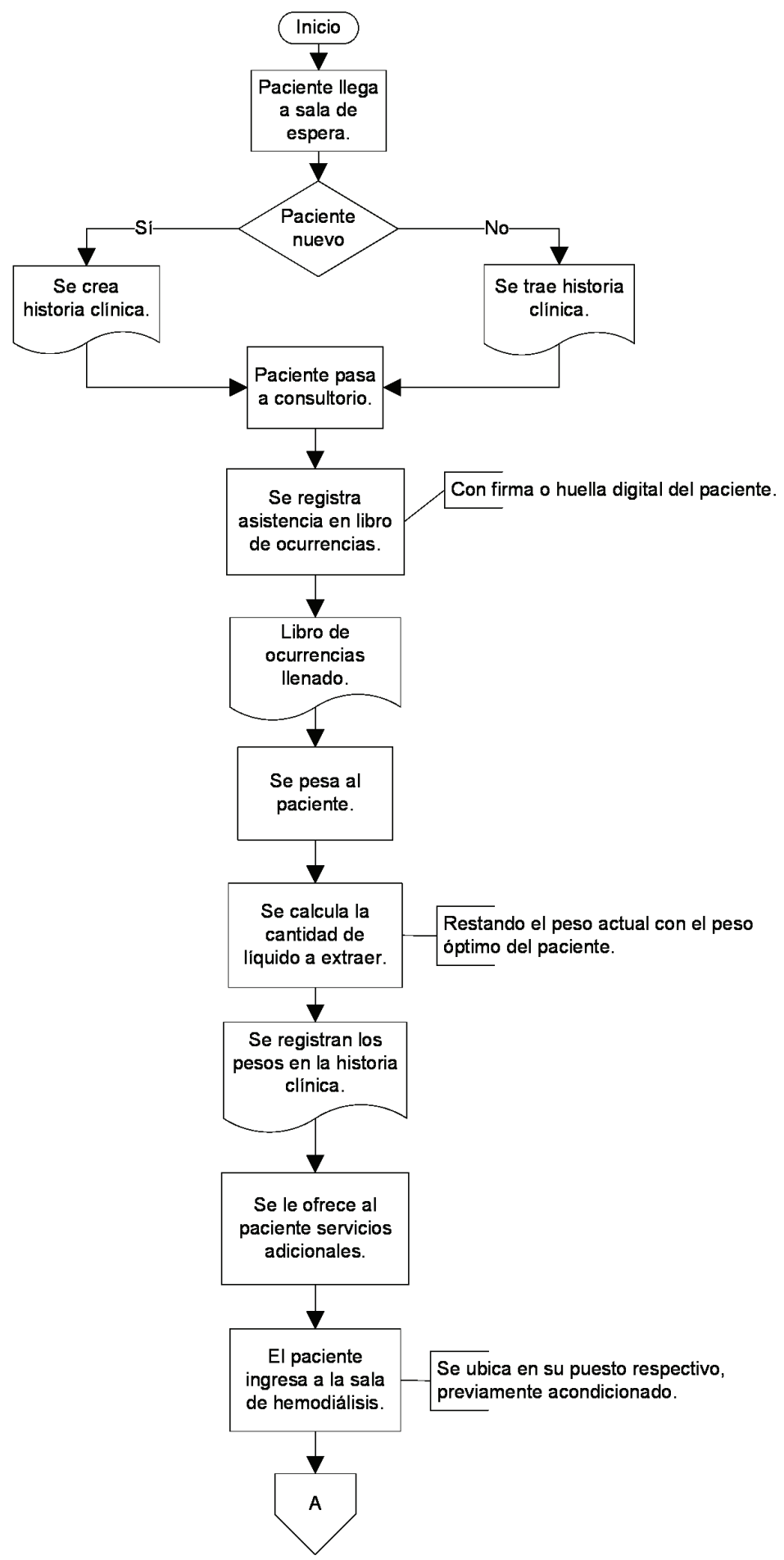

(continúa) 
(continuación)

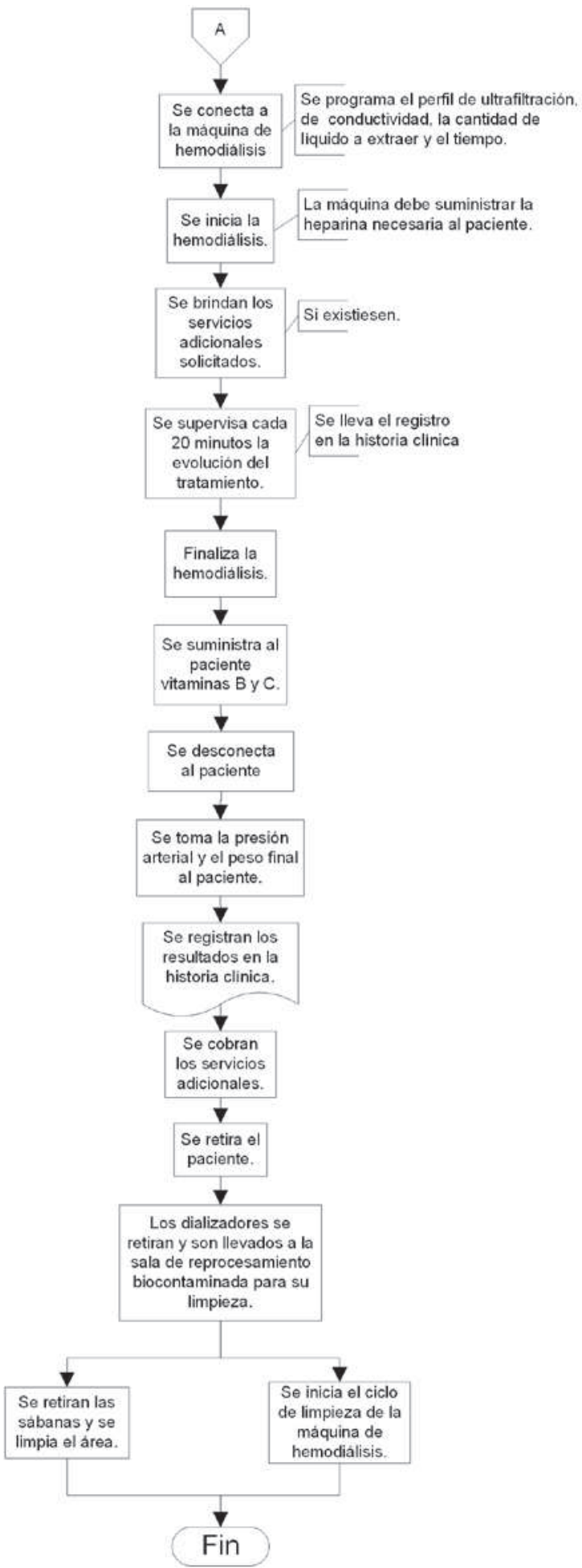




\section{Diagrama de purificación del agua}

Agua dura (potable)

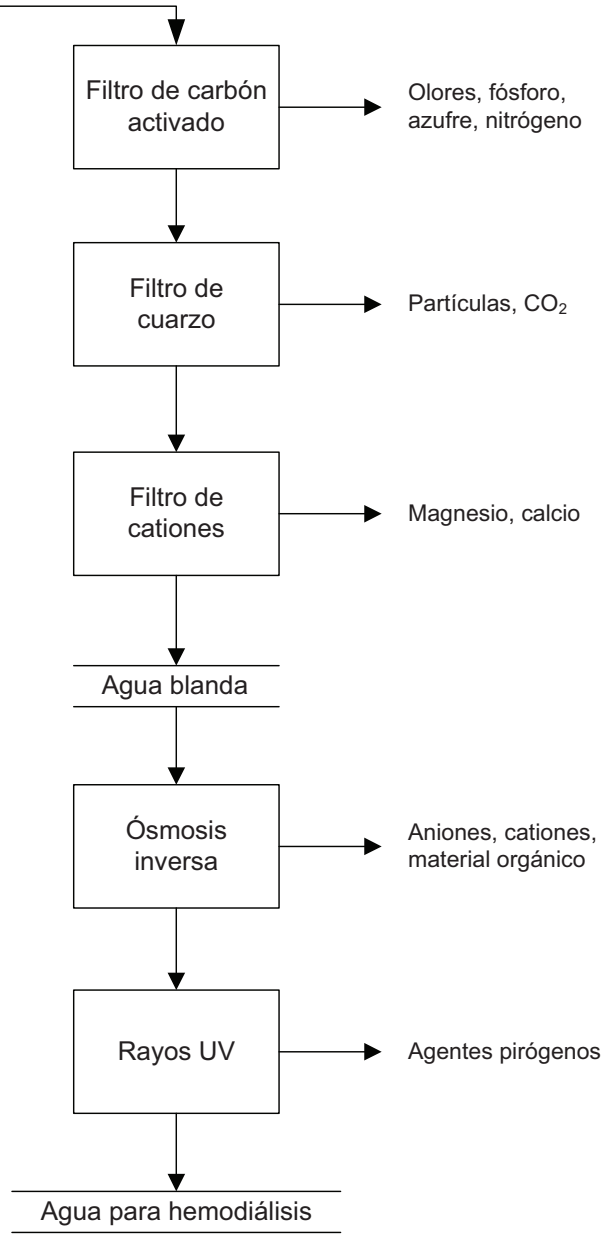




\subsection{Resguardo de la calidad}

\subsubsection{Calidad del proceso y del servicio}

El centro de hemodiálisis buscará mantener elevados niveles de calidad tanto en el proceso de hemodiálisis como en el servicio brindado, por lo que se contará con suficiente personal altamente capacitado para que el cliente reciba la atención que necesita. Los insumos utilizados serán todos procedentes de proveedores registrados en el Digemid y con registro sanitario.

Todos los ambientes tendrán un apropiado sistema de ventilación y renovación de aire.

Las máquinas utilizadas poseerán la garantía respectiva y recibirán el mantenimiento preventivo adecuado periódicamente. Finalmente, todos los instrumentos y máquinas utilizadas serán debidamente esterilizados o descartados, según corresponda.

\subsubsection{Medidas de resguardo de la calidad}

Se elaboró un plan de calidad para mantener un elevado nivel de calidad, el cual se muestra a continuación: 
Tabla 5

Plan de calidad

\begin{tabular}{|c|c|c|c|c|}
\hline Actividad & $\begin{array}{l}\text { ¿Qué se } \\
\text { controla? }\end{array}$ & $\begin{array}{l}\text { ¿Quién } \\
\text { controla? }\end{array}$ & $\begin{array}{l}\text { ¿Cómo } \\
\text { controla? }\end{array}$ & $\begin{array}{l}\text { Acciones por } \\
\text { incumplimiento }\end{array}$ \\
\hline $\begin{array}{l}\text { Ingreso } \\
\text { de paciente }\end{array}$ & $\begin{array}{l}\text { Registro de } \\
\text { asistencia }\end{array}$ & Médico & $\begin{array}{l}\text { Registro } \\
\text { en Libro de } \\
\text { Ocurrencias } \\
\end{array}$ & $\begin{array}{l}\text { Paciente firma o } \\
\text { coloca huella digital }\end{array}$ \\
\hline $\begin{array}{l}\text { Acondiciona- } \\
\text { miento del puesto }\end{array}$ & $\begin{array}{l}\text { Cumplimiento } \\
\text { de acondicio- } \\
\text { namiento }\end{array}$ & Enfermero jefe & Checklist & $\begin{array}{l}\text { Correcciones inme- } \\
\text { diatas de acondicio- } \\
\text { namiento }\end{array}$ \\
\hline $\begin{array}{l}\text { Preparación de } \\
\text { equipo para HD }\end{array}$ & $\begin{array}{l}\text { Estado del } \\
\text { filtro y com- } \\
\text { probación } \\
\text { residual }\end{array}$ & $\begin{array}{l}\text { Técnico de Sala } \\
\text { de Reprocesa- } \\
\text { miento }\end{array}$ & $\begin{array}{l}\text { Inspección } \\
\text { visual y } \\
\text { pruebas de } \\
\text { residuos }\end{array}$ & Reprocesar filtro \\
\hline $\begin{array}{l}\text { Proceso de } \\
\text { hemodiálisis }\end{array}$ & $\begin{array}{l}\text { Riesgos } \\
\text { biológicos }\end{array}$ & $\begin{array}{l}\text { Enfermero asis- } \\
\text { tencial }\end{array}$ & $\begin{array}{l}\text { Indicadores } \\
\text { en máquina } \\
\text { de HD }\end{array}$ & $\begin{array}{l}\text { Ajuste del proceso / } \\
\text { Suministro de medi- } \\
\text { camentos }\end{array}$ \\
\hline $\begin{array}{l}\text { Proceso de } \\
\text { hemodiálisis }\end{array}$ & $\begin{array}{l}\text { Estado del } \\
\text { paciente }\end{array}$ & $\begin{array}{l}\text { Enfermero asis- } \\
\text { tencial }\end{array}$ & $\begin{array}{l}\text { Inspección } \\
\text { visual / Indica- } \\
\text { dores médicos }\end{array}$ & $\begin{array}{l}\text { Suministro de } \\
\text { medicamentos }\end{array}$ \\
\hline $\begin{array}{l}\text { Proceso de } \\
\text { hemodiálisis }\end{array}$ & $\begin{array}{l}\text { Estado final } \\
\text { del paciente }\end{array}$ & $\begin{array}{l}\text { Enfermero asis- } \\
\text { tencial }\end{array}$ & $\begin{array}{l}\text { Toma de pre- } \\
\text { sión y peso, e } \\
\text { ingreso en his- } \\
\text { toria clínica }\end{array}$ & $\begin{array}{l}\text { Suministro de } \\
\text { medicamentos }\end{array}$ \\
\hline $\begin{array}{l}\text { Proceso de } \\
\text { hemodiálisis }\end{array}$ & $\begin{array}{l}\text { Proceso } \\
\text { completo }\end{array}$ & Enfermero jefe & $\begin{array}{l}\text { Registro en } \\
\text { Libro de } \\
\text { Ocurrencias }\end{array}$ & $\begin{array}{l}\text { Informar a enfermero } \\
\text { asistencial para } \\
\text { realizar acciones } \\
\text { correctivas }\end{array}$ \\
\hline $\begin{array}{l}\text { Purificación } \\
\text { de agua }\end{array}$ & $\begin{array}{l}\text { Nivel de } \\
\text { pureza en la } \\
\text { salida de } \\
\text { cada filtro }\end{array}$ & $\begin{array}{l}\text { Técnico de } \\
\text { equipos }\end{array}$ & Checklist & $\begin{array}{l}\text { Ajuste de especifica- } \\
\text { ciones / Cambio de } \\
\text { filtros / Mantenimiento }\end{array}$ \\
\hline $\begin{array}{l}\text { Purificación } \\
\text { de agua }\end{array}$ & $\begin{array}{l}\text { Presión del } \\
\text { agua }\end{array}$ & $\begin{array}{l}\text { Técnico de } \\
\text { equipos }\end{array}$ & Checklist & $\begin{array}{l}\text { Ajuste de } \\
\text { especificaciones / } \\
\text { Mantenimiento }\end{array}$ \\
\hline
\end{tabular}

(continúa) 
(continuación)

\begin{tabular}{|c|c|c|c|c|}
\hline Actividad & $\begin{array}{l}\text { ¿Qué se } \\
\text { controla? }\end{array}$ & $\begin{array}{l}\text { ¿Quién } \\
\text { controla? }\end{array}$ & $\begin{array}{l}\text { ¿Cómo } \\
\text { controla? }\end{array}$ & $\begin{array}{l}\text { Acciones por } \\
\text { incumplimiento }\end{array}$ \\
\hline $\begin{array}{l}\text { Limpieza } \\
\text { de filtro }\end{array}$ & $\begin{array}{l}\text { Cantidad de } \\
\text { reúsos }\end{array}$ & $\begin{array}{l}\text { Técnico de Sala } \\
\text { de Reprocesa- } \\
\text { miento }\end{array}$ & $\begin{array}{l}\text { Registro en } \\
\text { expediente } \\
\text { del filtro }\end{array}$ & Cambio de filtro \\
\hline $\begin{array}{l}\text { Limpieza } \\
\text { de filtro }\end{array}$ & $\begin{array}{l}\text { Presencia } \\
\text { de agentes } \\
\text { esterilizantes }\end{array}$ & $\begin{array}{l}\text { Técnico de Sala } \\
\text { de Reprocesa- } \\
\text { miento }\end{array}$ & $\begin{array}{l}\text { Pruebas de } \\
\text { detección de } \\
\text { químicos resi- } \\
\text { duales }\end{array}$ & $\begin{array}{l}\text { Reprocesamiento } \\
\text { de filtro }\end{array}$ \\
\hline $\begin{array}{l}\text { Limpieza } \\
\text { de filtro }\end{array}$ & $\begin{array}{l}\text { Verificar que } \\
\text { las fibras se } \\
\text { encuentren } \\
\text { abiertas }\end{array}$ & $\begin{array}{l}\text { Técnico de Sala } \\
\text { de Reprocesa- } \\
\text { miento }\end{array}$ & $\begin{array}{l}\text { Prueba de } \\
\text { volumen }\end{array}$ & Cambio de filtro \\
\hline $\begin{array}{l}\text { Limpieza } \\
\text { de filtro }\end{array}$ & $\begin{array}{l}\text { Verificar que } \\
\text { las fibras es- } \\
\text { tén enteras }\end{array}$ & $\begin{array}{l}\text { Técnico de Sala } \\
\text { de Reprocesa- } \\
\text { miento }\end{array}$ & $\begin{array}{l}\text { Prueba de } \\
\text { presión }\end{array}$ & Cambio de filtro \\
\hline Limpieza de filtro & $\begin{array}{l}\text { Confirmar } \\
\text { volumen de } \\
\text { germicida. } \\
\text { Verificar lim- } \\
\text { pieza y que } \\
\text { no haya fugas }\end{array}$ & $\begin{array}{l}\text { Técnico de Sala } \\
\text { de Reprocesa- } \\
\text { miento }\end{array}$ & $\begin{array}{l}\text { Inspección } \\
\text { visual }\end{array}$ & $\begin{array}{l}\text { Reprocesamiento de } \\
\text { filtro }\end{array}$ \\
\hline $\begin{array}{l}\text { Calidad de vida } \\
\text { del paciente }\end{array}$ & $\begin{array}{l}\text { Alimentación } \\
\text { y nivel de nu- } \\
\text { trición }\end{array}$ & Nutricionista & $\begin{array}{l}\text { Evaluación nu- } \\
\text { tricional cada } \\
\text { tres meses }\end{array}$ & $\begin{array}{l}\text { Cambio } \\
\text { de dieta diaria }\end{array}$ \\
\hline $\begin{array}{l}\text { Calidad de vida } \\
\text { del paciente }\end{array}$ & Salud mental & Psicólogo & $\begin{array}{l}\text { Evaluación } \\
\text { psicológica } \\
\text { cada mes }\end{array}$ & Terapias varias \\
\hline $\begin{array}{l}\text { Calidad de vida } \\
\text { del paciente }\end{array}$ & $\begin{array}{l}\text { Problemas } \\
\text { sociales }\end{array}$ & Asistente social & $\begin{array}{l}\text { Evaluación so- } \\
\text { cial cada mes }\end{array}$ & $\begin{array}{l}\text { Orientación y educa- } \\
\text { ción de pacientes y } \\
\text { familiares }\end{array}$ \\
\hline
\end{tabular}

Elaboración propia. 
Asimismo, se deberá cumplir con los siguientes objetivos:

- Alcanzar la dosis mínima de diálisis en el $85 \%$ de los pacientes, la que será determinada mediante el empleo de los siguientes indicadores:

$\mathrm{Kt} / \mathrm{V}$ : Aclaramiento fraccional de urea

PRU: Porcentaje de reducción de urea

En la tabla 6 se puede apreciar la dosis ideal mínima de hemodiálisis para pacientes con tres sesiones a la semana.

En la evaluación del cumplimiento de la dosis mínima de diálisis, se exigirá un $\mathrm{Kt} / \mathrm{V} \geq 1,3$.

Tabla 6

Dosis mínima por hemodiálisis

\begin{tabular}{lcc}
\hline & Kt/V & PRU \\
\hline Mujeres & $\geq 1.6$ & $\geq 75 \%$ \\
Menores de $50 \mathrm{~kg}$ de peso seco & $\geq 1.5$ & $\geq 73 \%$ \\
Diabéticos & $\geq 1.5$ & $\geq 73 \%$ \\
Varones de más de $50 \mathrm{~kg}$ & $\geq 1.3$ & $\geq 70 \%$ \\
\hline
\end{tabular}

Fuente: Base para contratación de servicio de atención ambulatoria de hemodiálisis (2009).

Elaboración propia.

- El 80\% o más de los pacientes deberá tener un tiempo de diálisis por sesión mayor o igual a tres horas y media.

- Remoción precisa de fluidos del paciente, alcanzando el peso seco al final del tratamiento, con un margen de error $\pm 10 \%$ de la cantidad de ultrafiltración programada, teniendo en cuenta la tolerancia hemodinámica del paciente.

- Asegurar la calidad del agua usada. Recuento de bacterias en agua para hemodiálisis menor a 100 UFC (unidades formadoras de colonias) y en solución de hemodiálisis menor a 2,000 UFC. El control debe ser mensual y estar registrado. 


\section{- Reprocesamiento de dializadores:}

- Solo está permitido el reprocesamiento de dializadores de pacientes negativos para hepatitis B, C y VIH.

- El reprocesamiento debe realizarse en forma estandarizada, automatizada o manual, según los estándares internacionales.

- El reactivo que se use deberá ser sometido a control. Se contará con probetas graduadas (no vidrio) para la medición del volumen residual de los dializadores.

- El agua utilizada para diluir los desinfectantes para reprocesamiento será agua procesada por ósmosis inversa de igual calidad que el agua usada para diálisis.

- Las líneas arteriales y/o venosas no serán reprocesadas.

- Tratamiento de agua. El agua utilizada para el tratamiento de hemodiálisis debe ser obtenida mediante proceso de ósmosis inversa y se debe realizar el control y registro de los siguientes parámetros, de acuerdo con las guías para el control físico químico del agua para diálisis AAMI (American Association of Medical Instrumentation):

- Medición diaria de la conductividad de $\mathrm{pH}$ del agua tratada.

- Control y registro diario de la dureza del agua.

- Control y registro mensual de sodio, potasio y cloramina.

- Control y registro mensual microbiológico (cultivo) del agua tratada.

- Control y registro semestral del nivel de endotoxinas del agua tratada.

- El programa de desinfección del sistema de distribución de agua debe considerar:

i. Desinfección quincenal de las líneas de agua purificada

ii. Sanitización quincenal de equipos

iii. Limpieza y desinfección semestral de cisternas y/o tanques elevados

- El agua para hemodiálisis debe ser almacenada en un tanque de material inerte.

\subsubsection{Niveles de satisfacción del cliente}

Como medidas para mantener un elevado nivel de satisfacción de nuestros clientes se aplicarán pruebas psicológicas, como mínimo una vez al mes, y pruebas para medir el nivel de calidad de vida al inicio del tratamiento de los pacientes nuevos, y semestralmente a los pacientes antiguos. 
Asimismo, se realizará una evaluación social mensual a cada paciente, llevada a cabo por un asistente social; además, se contará con un programa anual de educación para el paciente y los familiares basado en charlas, videos u otros materiales educativos, que permitan el conocimiento sobre las modalidades de tratamiento de la uremia, las ventajas del trasplante renal, de la diálisis peritoneal y de las medidas preventivas y autocuidados que se deben guardar en relación con su enfermedad.

También se efectuarán encuestas con una periodicidad mensual respecto del servicio de hemodiálisis y sobre los servicios adicionales que se brindarán, con el fin de conocer el nivel de satisfacción que tienen con respecto a los servicios y encontrar posibilidades de mejora.

Por otro lado, en caso de retraso injustificado en la ejecución de las prestaciones objeto del contrato con EsSalud, se aplicará una penalidad por cada día de atraso hasta por un máximo equivalente al diez por ciento (10 \%) del monto del contrato vigente o, de ser el caso, del ítem que debió ejecutarse. Adicionalmente, se aplicará una penalidad hasta del dos por ciento (2\%) del monto total de la factura mensual al contratista que incurra en los siguientes casos:

a) El dializador podrá ser reutilizado (solo para el caso de sesiones con reúso) únicamente si el volumen de su cámara interna se mantiene sobre ochenta por ciento $(80 \%)$ del volumen inicial y/o hasta un máximo a veinte (20) veces; de no ser así, dará lugar a una penalidad equivalente al uno por ciento (1\%) del monto total de la factura del período de ejecución del contrato. La prueba para verificar el volumen de los dializadores se practicará tomando al azar un número de ellos a criterio del supervisor.

b) Ausencia comprobada de uno o más de los siguientes integrantes del personal: médico nefrólogo, enfermera(s), técnico de mantenimiento, técnico de reúso, técnico(s) de sala, dará lugar a una penalidad equivalente al dos por ciento ( $2 \%)$ del monto total de la factura del periodo de ejecución del contrato.

c) La cuantificación de la diálisis se medirá usando el indicador $\mathrm{Kt} / \mathrm{V}$, el cual debe ser igual o mayor a 1,3. Si el número de pacientes que no alcanzan dicho indicador excede al quince por ciento (15\%) de su población evaluada, se aplicará una penalidad equivalente al dos por ciento $(2 \%)$ del monto total de la factura del periodo de ejecución del contrato. 
d) El $80 \%$ de los pacientes o más debe cumplir con una programación de tiempo de diálisis mayor o igual a tres horas y media. Si el porcentaje de pacientes no alcanza el referido indicador, y este es menor o igual al $79 \%$ de su población evaluada, se aplicará una penalidad equivalente al dos por ciento (2\%) del monto total de la factura del período de ejecución del contrato.

e) El incumplimiento de las Normas de Bioseguridad estipuladas en las bases y del Manual de Bioseguridad en cualquiera de los procesos de atención al paciente dará lugar a una penalidad equivalente al dos por ciento (2\%) del monto total de la factura del periodo de ejecución del contrato.

f) En caso de que se comprobara que una máquina de hemodiálisis es utilizada sin las alarmas operativas que garanticen la seguridad del tratamiento, se aplicará una penalidad equivalente al uno por ciento (1\%) del monto total de la factura del periodo de ejecución del contrato.

g) En caso de comprobarse que los equipos y/o insumos necesarios de reanimación cardiopulmonar no se encuentren operativos, se aplicará una penalidad equivalente al dos por ciento (2\%) del monto total de la factura del periodo de ejecución del contrato.

h) El incumplimiento de las especificaciones técnicas, consignadas como observaciones en el Libro de Ocurrencias para su cumplimiento inmediato, y que sean reiterados por escrito en dicho libro en más de una oportunidad, ocasionará una penalidad equivalente al dos por ciento $(2 \%)$ del monto total de la factura del periodo de ejecución del contrato.

i) La no remisión de la información solicitada que se refiere al proceso de registro de información, ocasionará una penalidad equivalente al uno por ciento (1\%) del monto total de la factura del periodo de ejecución del contrato.

j) De comprobarse que la tasa de seroconversión ${ }^{1}$ es mayor a la esperada para servicios contratados (comparada con la tasa de seroconversión del año anterior), se aplicará la penalidad equivalente al dos por ciento $(2 \%)$ del monto total de la factura del periodo de ejecución del contrato.

1 Aparición de anticuerpos detectables en suero sanguíneo como resultado de una infección o inmunización. 


\section{EVALUACIÓN DEL IMPACTO SOCIAL}

El presente proyecto tiene como finalidad la instalación de un centro de hemodiálisis para el tratamiento de pacientes diagnosticados con insuficiencia renal crónica, cuyo objetivo es brindar un servicio de alta calidad y ofrecer servicios adicionales al de la hemodiálisis para mayor comodidad y satisfacción de los pacientes.

El impacto social de este proyecto es de considerable valor, pues no solo se debe tener en cuenta el beneficio adicional a favor de los accionistas e inversionistas de la empresa, sino el mejoramiento de la calidad de vida de los pacientes que sufren de insuficiencia renal crónica y el de su entorno familiar y social.

Por otro lado, además de contribuir con la mejora de la salud en el Perú, el centro de hemodiálisis servirá como una fuente de trabajo para los profesionales de la salud, quienes se desarrollarán en su especialidad y formarán parte del crecimiento de la empresa.

\section{CONCLUSIONES Y RECOMENDACIONES}

- La instalación y puesta en funcionamiento de un centro de hemodiálisis en la ciudad de Lima es viable técnica y comercialmente, pues existe tecnología disponible y una demanda no cubierta que necesita del servicio ofrecido.

- La demanda de este servicio va en aumento año tras año y la oferta es insuficiente, por lo que la competencia que se pueda presentar no es una amenaza significativa.

- Para determinar el tamaño y disposición de las instalaciones se deben tener en cuenta los requerimientos y especificaciones establecidos por EsSalud para la implementación de un centro de hemodiálisis.

- Se recomienda evaluar la posibilidad de ampliar un turno adicional para el centro de hemodiálisis durante la noche (de 23:00 a 2:00 horas) para ofrecer el servicio de hemodiálisis a pacientes o entidades en forma privada.

- Se recomienda evaluar la posibilidad de abrir centros de hemodiálisis ubicados en otros distritos, para cubrir la demanda desatendida independientemente del nivel socioeconómico. 
- Se recomienda evaluar la posibilidad de realizar un estudio de viabilidad de establecer una cadena de centros de hemodiálisis que ofrezcan servicios adicionales.

- Se recomienda analizar otros segmentos de mercado que eventualmente podrían ser atendidos, como el caso de las personas menores de 55 años, que representan alrededor del $40 \%$ de pacientes de hemodiálisis.

- Se recomienda investigar el beneficio/costo de la tecnología que ofrecen las empresas chinas, presumiblemente más económicas.

- Se recomienda contar con un plan de rotación de las máquinas de hemodiálisis que se encuentran almacenadas para emergencias con las que se utilizan regularmente, con el fin de que el desgaste de los equipos sea parejo.

\section{REFERENCIAS}

Baxter. (s. f.). Información sobre productos. Recuperado de http://www. baxter.com/

Braun, B. (s. f.). Información sobre productos. Recuperado de http:// www.bbraun.com/

Fressenius. (s. f.). Información sobre productos. Recuperado de http:// www.fresenius.se/

Gómez, M. (2009). Anemia en la Enfermedad Renal Crónica. Ponencia presentada en curso de capacitación para Fuerza de Ventas de un laboratorio farmacéutico. Lima.

Hersil. (s. f.). Información sobre productos. Recuperado de http://www. hersil.com.pe/

Ipsos Apoyo. (2009). Perfil del Adulto Mayor 2008 (Informe impreso).

Médicos del Perú. (s. f.). Essalud: ¿Competir para gastar más y prestar menos servicios? Recuperado de http://www.medicosdelperu.com. pe/articulos-essalud.htm

Mi empresa. (s.f.). Convocatorias de Negocio. Recuperado de http://www. miempresa.gob.pe/compras_estatales/mostrar_convocatorias_ negocio.php?d=\&grp=S\%20_07\&ob_param=ent_descri\&p=250 
National Kidney Foundation. (s. f.). Commentaries. Recuperado de http:// www.kidney.org/professionals/kdoqi/guidelines_commentaries. cfm

Nipro. (s. f.). Información sobre productos. Recuperado de http://www. nipro.com/

Seguro Social de Salud del Perú. (s. f.). Nuestra Institución. Recuperado de http://www.essalud.gob.pe/contenido.php?id=30

Trifarma. (s. f.). Información sobre productos. Recuperado de http:// www.medifarma.com.pe/

Universidad Peruana Cayetano Heredia. (s. f.). DUGIC: Biblioteca Virtual. Recuperado de http://www.upch.edu.pe/vrinve/dugic/

Zevallos, E. (2006). Tratamiento de la Enfermedad Crónica Terminal. Boletín Tecnológico, 20. 